\title{
Playware Explorations in Robot Art
}

\author{
Lund, Henrik Hautop ; Pagliarini, Luigi
}

Published in:

Proceedings of 2nd International Conference on Robot Intelligence and Applications

Publication date:

2013

Link back to DTU Orbit

Citation (APA):

Lund, H. H., \& Pagliarini, L. (2013). Playware Explorations in Robot Art. In Proceedings of 2nd International Conference on Robot Intelligence and Applications Springer.

\section{General rights}

Copyright and moral rights for the publications made accessible in the public portal are retained by the authors and/or other copyright owners and it is a condition of accessing publications that users recognise and abide by the legal requirements associated with these rights.

- Users may download and print one copy of any publication from the public portal for the purpose of private study or research.

- You may not further distribute the material or use it for any profit-making activity or commercial gain

- You may freely distribute the URL identifying the publication in the public portal

If you believe that this document breaches copyright please contact us providing details, and we will remove access to the work immediately and investigate your claim. 


\title{
Playware Explorations in Robot Art
}

\author{
Luigi Pagliarini ${ }^{1,2}$ Henrik Hautop Lund ${ }^{1}$ \\ ${ }^{1}$ Center for Playware, Technical University of Denmark, Building 326, 2800 Kgs. Lyngby, \\ Denmark \\ ${ }^{2}$ Academy of Fine Arts of Macerata, Via Berardi, 6. 62100, Macerata, Italy \\ \{luigi, hhl\}@playware.dtu.dk
}

\begin{abstract}
We describe the upcoming art field termed robot art. Describing our group contribution to the world of robot art, a brief excursion on the importance of the underlying principles, of the context, of the message and its semiotic is also provided, case by case, together with few hints on the recent history of such a discipline, under the light of an artistic perspective. Therefore, the aim of the paper is to try to summarize the main characteristics that might classify robot art as a unique and innovative discipline, and to track down some of the principles by which a robotic artifact can be considered - or not - an art piece, in terms of social, cultural and strictly artistic interest.
\end{abstract}

Keywords: Robot, Art, Kinetic, Sculpture, Cyber, Cyberpunk, Embodiment, Evolution, Modular, Holography, Metamorphic, Alife, Polymorphic, Intelligence, Virtual, Alive.

\section{Introduction}

We can find robots in science and technology, architecture, art, video clips, cinema, literature as well as in our own homes. Their presence is fast growing in all fields and sectors and is becoming consistent in industrial production, medicine and entertainment. Robotics, in short, is a new "language" that is permeating the whole social structure and incorporating within itself several charming practical and intellectual issues that are able to elicit the interest and the curiosity of many philosophers, artists, scientists, technologists and, overall, ordinary people. In this paper, we try to get a closer and more specific look at what we call robot art, to try to understand the differences which can be found between the conceiving and the designing of pure scientific and/or commercial robots and those that can be considered exclusively art oriented. We do that although Flusser [1] suggested, somehow "Scientists are computer artists avant la lettre, and the results of science are not some 'objective insights', but models for handling the computed" (and vice versa). In fact, contemporary robotics is the field in which the comprehension of human brain attempts to materialize. It is a topic that has always been transversal to scientific and human disciplines alike, and that has brought together research fields into neuroscience, engineering, computer science, biology, mathematics, psychology, and philosophy. Indeed, from literature we know

adfa, p. 1, 2011.

(c) Springer-Verlag Berlin Heidelberg 2011 
that embodying the biological neural system into machines (and machine bodies) is one of the most attractive and challenging "dreams" humans deal with. In recent time, we went through this topics - like for example in the Alive Art [2] and Polymorphic Intelligence [3] manuscripts - but here we will try to look at things under an actual and a historical point of view to summarize and synthesize in one single vision the resulting paradigm and conceptual approach, by focusing, specifically, on robot art.

\section{Recent Historical Paths}

We may hypothesize that the research in this field was started in the 1950s within the Cybernetic Serendipity at London's ICA [4], and, today it is hosted in many contemporary artistic and cultural events - as, for example, it happened in the specialized art events like Robodock, Robots at Play, ArtBots, in New Media events like Ars Electronica, Transmediale, and in more generalist art events, like in the Venice Biennale, and etc. The number of artists (and artists/scientists), and the complexity of their artifacts, grows rapidly and it becomes more difficult to track down both what has happened and what is happening. There are, certainly, few authors and art pieces which must be included in this brief history of recent robot art, even if, in art, only the time will tell what is to be considered art and what is not.

Amongst those of the last decade we could, for example, annoverate the work from Ken Goldberg, Telegarden (1995) [5], as turning point for the tele-robotics art concept. Indeed its tele-robotics installation allowed the users to control, watering and growing - thanks to a robot arm manipulated through a World Wide Web application - a real plant.

From the cyberpunk culture - an active and famous exponent is Chico Macmutrie with his Amorphic Robot Works (from 1992 on) [6] - straights ahead we come across the cyborgs.

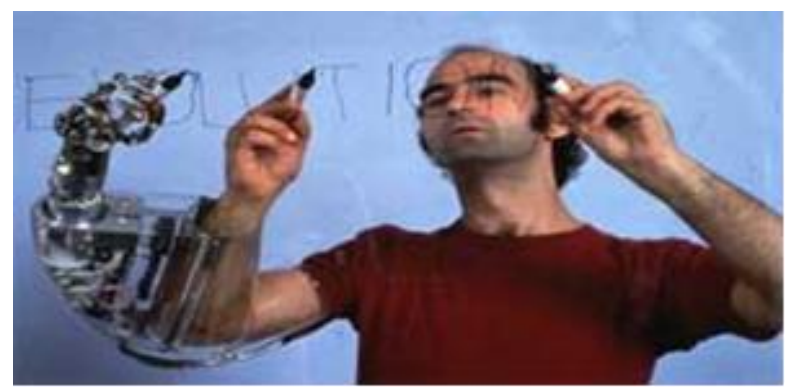

Fig. 1. Stelarc writing the word "Evolution" with his famous cyborganic experimentation the Third Hand.

Amongst those, the most emblematic figure is Stelarc [7], who basically opened, more than ever, the use of robotics in (body)art and revolutionized the meaning of robot art. It is, indeed, a different way to look at robot art pieces. He is one of the most important contemporary artist and his art pieces (e.g.: Third Hand Project, 1976, 1981, 1991 Fig. 1) are strikingly innovative under all senses. Based on the cyberpunk 
vision, the Stelarc performances tilt the approach to robotics as an external device to strongly emphasize the human embodiment.

Another powerful artist, which embraces the same philosophy is one of the founders of the "La Fura dels baus", Marcel.lì Antùnez Roca, with his Membrana Project (i.e.: Protomembrana (Fig. 2) and Hipermembrana) [8], by which, as for Stelarc, he explores the layering possibilities of human-machine-media interaction and interrelation. Which is, indeed, one of the most hot topics in Robotic Art, at the moment.

The Haile Robot developed by Gil Weinberg, Scott Driscoll and Travis Thatcher [9] is interesting because of its own way of exploring the concept of machine creativity and, parallel, the ability of robots to cooperate and collaborate (in what the author calls musicianship) with humans while producing art, run-time.

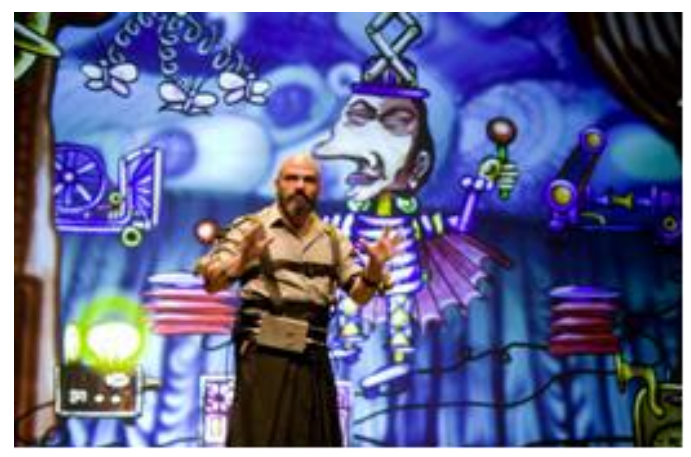

Fig. 2. Marcel.li Protomembrana during Robots at Play 2007.

Also, it is worth to spot Ximo Lizana's new research on 3D holographic projected sculptures (e.g.: the "Mid Air Shark", 2007. [10] Fig. 3). This technique opens a new horizon (we might name virtual robot art) to the robot art field here intended as a three dimensional object occupying a given physical space and interacting, by now in a naïve way - with the surrounding ambient.

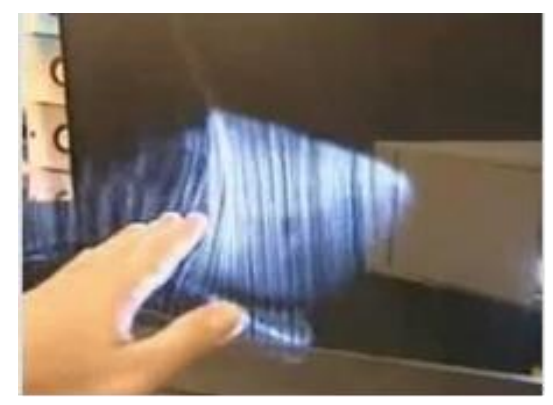

Fig. 3. A vistor interacting with the Mid Air Shark holographic projection, Ximo Lizana, 2007.

One different scenario is the sector of robot production and research that, more than robot art, could be defined as art oriented robots. They are robotic application intended to serve the world of art (e.g. Gibson's "Robot Guitar" [11]), which are a bit 
out of context here, but still not too far away from what we might want to call robot art, in future.

Finally, one must considered works like those by Hiroshi Ishiguro's Geminoid (Fig 4 left [12]), an example of how invasive can technology be; on the opposite side, Nemo Gould's Armed and Dangerous (Fig 4 right, [13]) representing the typical artistic ironic sight given to the world of war oriented robots; and many others.
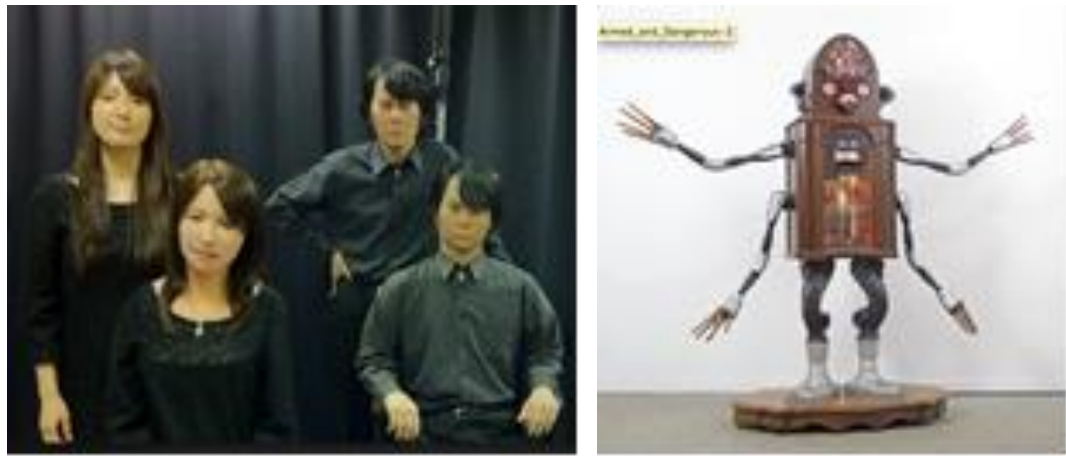

Fig. 4. (Left) Hiroshi Ishiguro's Geminoid. (Right) Nemo Gould's Armed and Dangerous.

\section{Our Contributions}

As we tried to shortly outline above, robot art is a field that is consolidating, by showing a growing number of new aesthetical, philosophical, and artistic methods and approaches to the creation of artifacts. Such artifacts can be traditional art pieces (e.g. paintings, sculptures, performances, tells, etc.) or modern ones (e.g. innovative ideas, behaviors, robots themselves, etc.).

In the last ten years, within the exciting exploration and amazing exploitation of conceptual and aesthetical possibilities we tried to give our modest contribution to the field of robot art by producing both strictly artistic and art and science based models.

One good example of a scientific application that touches the borders of an art-like artifacts can be found in the Atron (Fig. 5) module, developed by Henrik Hautop Lund and colleagues [14]. 


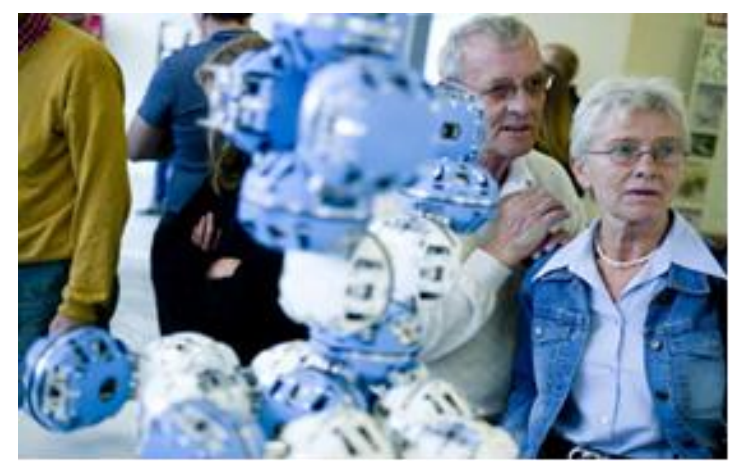

Fig. 5. The Atron modules exhibited at Brandts Museum, Odense, Denmark, 2007.

Atron modules is a self-assembling shape chain of robots-atoms that, by using mastered/centralized or collective A.I. "reasoning" changes its own shape along the time. This perpetual changing artifact could be located at the junction between the robot art and kinetic sculpture art fields.

Indeed, although at a first sight the robot behavior and shape resemble the old definition, on the other hand, the independency of the machine movements explore possibilities in kinetic sculptures so original to deserve a new definition as, for example, kinetic robot sculpture, robot metamorphic art, or so.

A different example of the evolution of the human-machine relationship imprinted by robot art works is in the 'full-loop' realized in LifeGrabber by Luigi Pagliarini in 2003 [15]. A webcam mounted on a robotic arm, controlled by a software written by the artist himself analyzes the audio/video inputs run-time, through a population of Alife agents which, in turn, influences both the audio/video output and the robot arm movements (therefore the future vision of the robot, see Fig. 6). While pointing at itself, this robot art piece gives birth to a 'self-observing machine', facing one of the most fascinating topics for future computer based art works, the philosophical problem of self-consciousness.

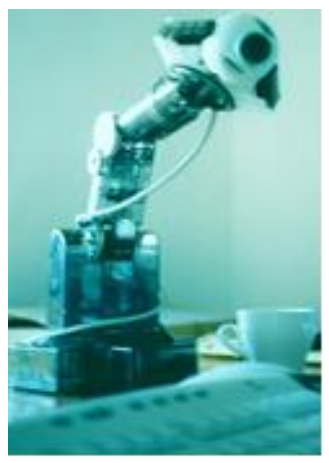

Fig. 1. The Robot Arm-Eye used in "LifeGrabber”, by Luigi Pagliarini. 2003. 
Further, inspired by the Gutai [16], Tanaka [16], Stelarc [7] and Marcel.li [8] (amongst others) we initiated an artistic investigation, which we term Modular Robotic Wearable (MRW). The Modular Robotic Wearable [17] thought was born in 2007 from both the research line in electronic and robotic art - called The SuperAvatars (see Fig. 7). MRW is related to Wearable Computing or WearComp - a branch of research on forms of human-computer interaction comprising a small body-worn computer (e.g. user programmable device) that is always on and always ready and accessible.

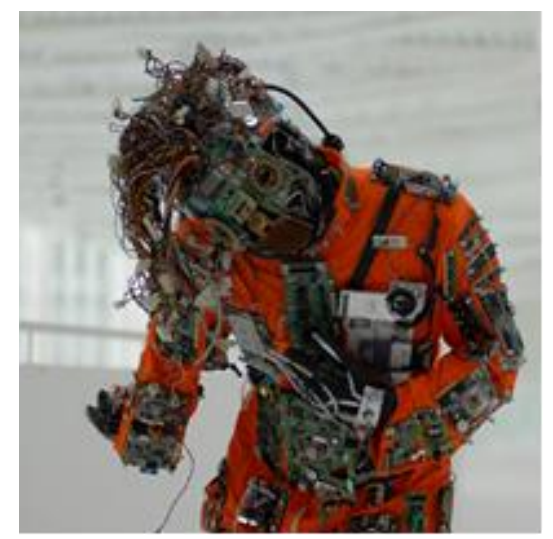

Fig. 2. "Fatherboard, the Superavatar", by Luigi Pagliarini. 2007.

The MRW merges this art inspiration and wearable computing inspiration with our research tradition on modular robotics $[14,18]$. It can be seen as a means for augmenting human interfaces both from virtual realities to the body and from the physical body to virtual realities and, in other words, MRW brings along new discoveries and potential research fields on exploring body action and reaction, limits and capabilities.

To explore cooperative creativity, we developed Music Tiles [18] (see Fig. 8 Left) and MusicTiles Magic Cubes [19] (see Fig. 8 Right) together with musician Peter Gabriel. MusicTiles allow anybody - novices, musicians, and expert composers - to remix songs (such as Peter Gabriel's hit songs) in a playful manner using virtual modular tiles, transforming the music fan from a passive listener to an active performer. Each tile is an instrument, and by putting them together in different configurations, the user activates different parts of each instrument, creating totally new versions of the hit songs. The MusicTiles Magic Cubes were developed as a physical realization and extension to the MusicTiles app to push users into real life social situations, as showcased at Roskilde Festival 2013 [20]. It is realized as a set of robotic music cubes that lets people interact with music as it is playing--they can activate or deactivate song elements by simply turning the cubes around. As a social playware it explores the cooperative creativity of robot art: the magic cubes seamless push the users into social play dynamics resulting in the users interacting and cooperating in their play to create and perform their collective new hit song versions. Here, the robot art mediates social creativity. 

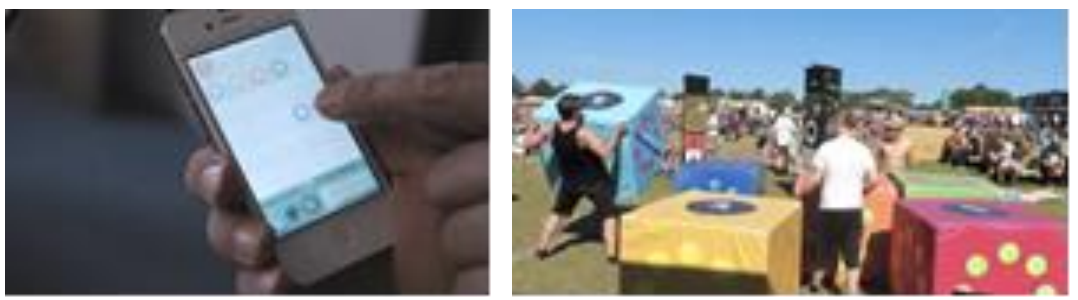

Fig. 3. (Left) MusicTiles app and (Right) MusicTiles MagicCubes by Henrik Hautop Lund, Luigi Pagliarini, Peter Gabriel 2012/13.

\section{$4 \quad$ Lessons Learned}

Art History, Robotics and Art belong together and chase each other since the idea of robotics itself was born (1890, see Karel Čapek's R.U.R. [21], Fig. 9). This process by which art keeps on shaping and indirectly cooperating with a hyper rational and scientific progressive conceptualization of what we could call self-sufficient automation, has no reliable law.

We could look for rules or look for repetitive and schematic behavior in such a process (i.e. by which art keeps on creating robotics) but it is principally impractical. What is sure is that, the more or less direct collaborative evolution of art and robotics, easy and straightforward at its beginning, is now getting much more complex and articulated since both the disciplines are facing an elevated, quick and multifaceted development. And just because of that, on the opposite, such a process becomes more and more unpredictable. The deformation of the starting point (i.e. robot as a substitute of humans' hard and repetitive works) is taking places in all of the directions, since it is not only hard work, it is not only repetitive but sometimes very creative and it is not even work or necessarily humans' like!

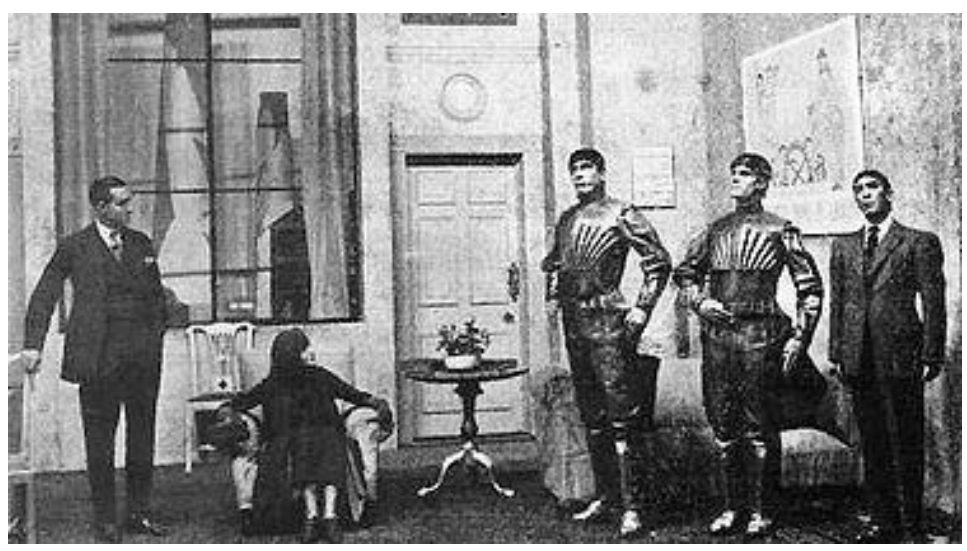

Fig. 9. A scene from the play R.U.R., 1921. 
Nevertheless, we will try to outline what are the most significant crossing lines emerging from the brief description and review of robot art. They are:

1. An intensive work on the human-robot body that can be seen as outside shell, as well as inner side up to imitation or cloning. Evident examples are the Atsuko Tanaka's [6], Stellarc's [7], Pagliarini's [17], Lund's [14], and Ishiguro's [12] works. There are attempts to extend the human dimensions, feelings, perceptions, motions, and abilities. There seems to be a will to explore the limits of the human body to finally reinvent it throughout new functionalities. It is of course an ancestral dream that moves away from a world made of pure imagination and steps out in to a kind of reality, good or bad as it can be;

2. An amazing attempt for cooperative creativeness as shown in Marcel-li's [8] and Pagliarini's [18] and Lund's [18 and 19] works. Robotics offers the possibility, through manipulation of artifacts and exoskeletons to start up a dialogue between the machines and humans. They, accordingly to the tasks, differ in speed, sharpness, effectiveness (i.e. time and space), "intelligence" and, mostly, in output production. Most of the scientists and almost all of the artists see such a thing as an endless resource for creativity- if we view it as a cooperative and collaborative process - to open a ping-pong that might end up with quite special and original outcome and, therefore, for aesthetic artifacts production;

3. An exploration of ambient related intelligence as revealed by Ihnatowicz [16] first. No doubts, art expresses a special cut of the world, a particular vision of reality as it flows and, because of that, is fully sensitive to external events. Robotics, basically made of sensors that constantly try capturing and measuring the surrounding habitat, seems to be born to play with such an artistic attitude. At the very moment there are already thousands of artists trying to apply world sensing electronics (i.e. from cameras up to proximal and distance sensors) to incorporate such information in their artistic productions (i.e. from painting to acting, from sculputure to music). It is the widest and most popular branch in what we are naming as robot art;

4. A number of art oriented machines. They are robots that can help on realizing art pieces or mediating the process of art production. They go from the most obvious, industrial and commercial ones - as for the case of Gibson's auto tuning guitar (i.e.: Robot Guitar [11]), to the most amazing, unpredictable and handicraft ones - as for the case of Charles Karim Aweida's work [22] where a wind simulation algorithm and a robot arm are used to build up an art piece made of nails on wood;

5. Pure artistic robotics in which the elaboration of the social, human and ecosystem conditions are. Examples can be found in the Nemo Gould's "Armed and Dangerous" piece [13] where an ironical approach is used to protest again a certain research on war robots, or in Luigi Pagliarini's "Intelligenza" piece (see Fig. 10, [23]) where the human being and robots conditions blur in such a way that it is hard to say which of the two is at the center of the artifact. 


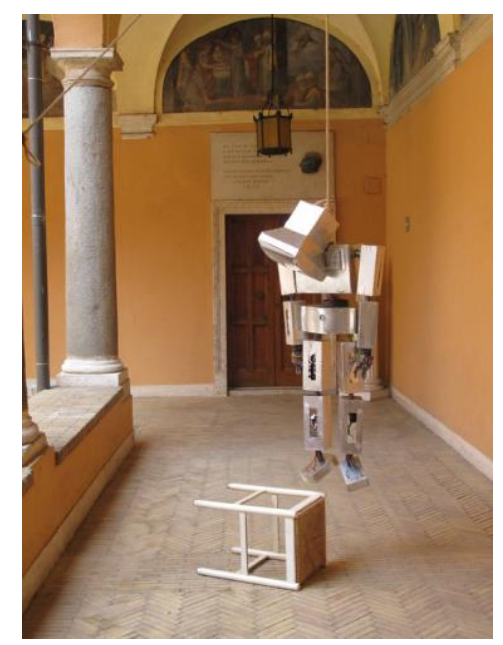

Fig. 10. Intelligenza by Luigi Pagliarini, 2010.

Besides that, of course there are and there will be many different and noble exceptions and mutations that will keep the evolution of the area funny and interesting.

\section{Conclusions}

As can be easily understood by reading through these few and mostly incomplete historical examples - we've been trying to assemble in a pathway to modernity - the robot art field mostly deals with the innovation and the exploration of the borders of human-machine relationship. In other words, robot artists focus on what we, formerly, defined as polymorphic intelligence [3], where the machine and human bodies and minds melt together to shape a single "knowledge". Indeed, they are, to some extends, the blade runners which try to prefigure futuristic scenarios that might appear along the human being (and machine) development and in the upcoming world. By creating robot art pieces they somehow materialize what we defined as the Alive Art principles (of unpredictability and perpetual change) [2] and therefore assert themselves for being one of the most important avant-garde both in art and in sciences such as biology, psychology, philosophy, etc.

\section{References}

1. Flusser, V.: Digital Apparition, (Digitaler Schein, Suhrkamp Verlag) in: Electronic Culture, edited by Timothy Druckrey. Aperture: New York (1996)

2. Pagliarini, L., Locardi, C., Vucic, V.: Toward Alive Art. In Proceedings of Virtual Worlds 2000. Second International Conference, J.C. Heudin (Ed.) Springer-Verlag Press (2000)

3. Pagliarini L.: Polymorphic Intelligence. In proceedings of The Twelfth International Symposium on Artificial Life and Robotics. AROB 12th '07. Oita, Japan (2007) 
4. Reichardt, J. (ed.) Cybernetic Serendipity. Studio International 1968, London, 10-11 (1968)

5. Goldberg, K., Mascha, M., Gentner, S., Rossman, J., Rothenberg, N., Sutter, C., Wiegley, J.: Beyond the Web: Manipulating the Real World. Computer Networks and ISDN Systems Journal, 28(1) (1995)

6. http://amorphicrobotworks.org/

7. http://www.stelarc.va.com.au/

8. http://www.marceliantunez.com/

9. Weinberg G., Godfrey M., Rea, A., Rhodes, J.: A Real-Time Genetic Algorithm in Human-Robot Musical Improvisation, Lecture Notes in Computer Science, Springer Press, (2007).

10. http://www.ximolizana.com/

11. http://www.gibson.com/robotguitar/

12. http://www.geminoid.jp/en/index.html

13. http://www.nemogould.com/portfolio-item/armed-and-dangerous/

14. Brandt, D. Christensen, D., Lund, H.H.: ATRON Robots:Versatility from SelfReconfigurable Modules. In Proceedings of IEEE Int. Conf. On Mechatronics and Automation, 2007. ICMA 2007, IEEE Press (2007)

15. http://www.neural.it/nnews/lifegrabber.htm

16. Kac, E.: Robotic Art Chronology, in Convergence, Volume 7, N. 1, 87-111 (2001)

17. Pagliarini, L., Lund, H.H.: Wearable Playware. In The 8th International Conference on Ubiquitous Robots and Ambient Intelligence. (pp. 9-13). IEEE (2011)

18. Pagliarini, L., Lund, H.H.: MagicTiles. ALife for Real and Virtual RoboMusic. In Proc. of 17th International Symposium on Artificial Life and Robotics, ISAROB, Japan (2012)

19. MusicTiles MagicCubes: http://www.youtube.com/user/HenrikHautopLund

20. http://roskilde-festival.dk/

21. http://en.wikipedia.org/wiki/R.U.R

22. http://cka.co/projects/representing_wind/

23. http://www.artificialia.com/intelligenza/ 